Article

\title{
Invasive Pneumococcal Disease in Adults in Portugal: The Importance of Serotypes 8 and 3 (2015-2018)
}

\author{
Catarina Silva-Costa ${ }^{+} \mathbb{D}$, Joana Gomes-Silva ${ }^{\dagger}$, Inês Teodoro, Mário Ramirez ${ }^{*} \mathbb{D}$, José Melo-Cristino \\ and on behalf of the Portuguese Group for the Study of Streptococcal Infections $\ddagger$
}

Faculdade de Medicina, Instituto de Microbiologia, Instituto de Medicina Molecular, Universidade de Lisboa, 1649-028 Lisboa, Portugal; anacosta@fm.ul.pt (C.S.-C.); jfsilva@medicina.ulisboa.pt (J.G.-S.);

i.teodoro@campus.ul.pt (I.T.); melo_cristino@fm.ul.pt (J.M.-C.)

* Correspondence: ramirez@fm.ul.pt; Tel.: +351-21-799-9460

+ These authors contributed equally to this work.

$\ddagger$ Membership of Portuguese Group for the Study of Streptococcal Infections is provided in the Acknowledgments.

check for updates

Citation: Silva-Costa, C.;

Gomes-Silva, J.; Teodoro, I.; Ramirez, M.; Melo-Cristino, J.; on behalf of the Portuguese Group for the Study of Streptococcal Infections. Invasive Pneumococcal Disease in Adults in Portugal: The Importance of Serotypes 8 and 3 (2015-2018). Microorganisms 2021, 9, 1016. https://doi.org/10.3390/ microorganisms 9051016

Academic Editors: David J. Allen and Ardanuy Carmen

Received: 12 April 2021

Accepted: 5 May 2021

Published: 8 May 2021

Publisher's Note: MDPI stays neutral with regard to jurisdictional claims in published maps and institutional affiliations.

Copyright: (c) 2021 by the authors. Licensee MDPI, Basel, Switzerland. This article is an open access article distributed under the terms and conditions of the Creative Commons Attribution (CC BY) license (https:/ / creativecommons.org/licenses/by/ $4.0 /)$.
Abstract: Increasing the uptake of the 13-valent pneumococcal conjugate vaccine (PCV13) in children is expected to alter the serotypes causing invasive pneumococcal disease (IPD) in adults due to herd protection. We characterized 2172 cases of adult IPD in 2015-2018 in Portugal after the introduction of PCV13 in the national immunization plan of 2015. Among the 58 detected serotypes, serotypes $8(n=413 ; 19 \%), 3(n=334 ; 15 \%), 22 \mathrm{~F}(n=148 ; 7 \%), 14(n=138 ; 6 \%)$, and $19 \mathrm{~A}(n=116 ; 5 \%)$ were the most frequent. Among PCV13 serotypes, 7F and 19A IPD decreased, but serotype 3 IPD remained stable. The non-PCV13 serotypes were a heterogeneous group, with serotypes $23 \mathrm{~A}$ and $23 \mathrm{~B}$ enriched among CSF cases; serotype 8 associated with younger patients; and serotypes 22F, 6C, and 31 associated with older patients. The continued increase of serotype 8 IPD was one of the drivers for the increased coverage of the 23-valent pneumococcal polysaccharide vaccine (PPV23; $80 \%$ in 2015-2018). Antimicrobial resistance was associated with older age and serotypes 6C, 11A, 14, 15A, 19A, and 19F. Three years after the introduction of PCV13 in the NIP with an uptake of $>95 \%$, the proportion of PCV13 serotypes causing IPD in adults stabilized in Portugal. The direct vaccination of adults may be important in preventing IPD in this age group.

Keywords: conjugate vaccine; polysaccharide vaccine; serotype; invasive disease; epidemiology; antimicrobial resistance

\section{Introduction}

The introduction of pneumococcal conjugate vaccines (PCVs) in children led to changes in the incidence and serotypes causing invasive pneumococcal disease (IPD), not only in vaccinated children but also in adults. In fact, initial data from the United States showed that more cases were averted by this herd protection than by the effects on the groups targeted by vaccination. The increasing use of the 23-valent polysaccharide vaccine (PPV23) and the approval of the 13-valent conjugate vaccine (PCV13) for use in adults also has the potential to further impact IPD in this age group. In Portugal, as elsewhere, the use of increasing valency PCVs in children led to changes in the serotypes causing IPD in adults [1-3]. However, although reaching a substantial vaccine coverage (around $63 \%$ ), the use of the PCVs through the private market and without reimbursement may have contributed to the persistence of vaccine serotypes as causes of IPD by creating an uneven distribution of the vaccine. The use of the 7-valent PCV (PCV7) in children led to a decrease in the proportion of PCV7 serotypes in adult IPD in Portugal in 2006-2008, with the most frequent serotypes being 3, 1, 7F, 19A, and 14 [3]. After the introduction of PCV13 for children vaccinations in 2010, a decline in the proportion of the additional serotypes included in PCV13 was observed in adult IPD, mostly driven by decreases in the proportion 
of serotypes 1, 5, 7F, and 19A, while serotype 3 remained an important serotype in IPD [1,2]. Concomitantly, serotypes not included in any PCV gained importance, with serotype 8 being of special concern and becoming a leading serotype in adult IPD in Portugal [1] and elsewhere [4-6]. Other emerging non-PCV13 serotypes in Portugal include the 22F, 11A, $9 \mathrm{~N}, 6 \mathrm{C}, 15 \mathrm{~B} / \mathrm{C}$, and 15A serotypes [1].

Despite the reductions in PCV13 serotypes, the fraction of adult IPD that is potentially vaccine-preventable remained high, with data from 2014 showing that PCV13 serotypes significantly persisted (38\%) and that isolates expressing PPV23 serotypes accounted for $75 \%$ of all adult IPD [1]. Though several medical associations issued age-based recommendations for vaccination with both PCV13 and PPV23 [7], the official guidelines of the Portuguese national health authority recommend vaccination only in risk groups [8]. There is no national data on the uptake of the pneumococcal vaccine in adults in Portugal, but a single-center study conducted in 2007 revealed that $<10 \%$ of individuals $\geq 65$ years had been vaccinated with PPV23 [9]. In 2015, PCV13 was introduced in the NIP for children, with doses given at 2, 4, and 12 months of age. Despite the expected low uptake of PCV13 in adults, the broader vaccine uptake achieved by universal childhood vaccination could potentially further impact adult IPD serotype distribution. Furthermore, 15- and 20-valent PCVs are applying for approval for use in adults and should reach the market soon $[10,11]$. The aims of this work were to document serotype changes and susceptibility patterns among pneumococci causing adult IPD following the introduction of PCV13 in the NIP for children and to evaluate the potential benefits of the increased valency vaccines.

\section{Materials and Methods}

Since 1999, the Portuguese Group for the Study of Streptococcal Infections has been monitoring invasive pneumococcal disease in Portugal through a laboratory-based surveillance system of 31 microbiology laboratories involving the collection and shipment of all IPD isolates to a central laboratory for characterization [12]. Though all laboratories were periodically contacted to submit isolates to the central laboratory, no audit was performed to ensure compliance, which may be variable in this type of study. A case of IPD was defined by the isolation of pneumococci from a normally sterile fluid, such as blood, cerebrospinal fluid (CSF), or pleural fluid, or the detection of pneumococcal DNA in a normally sterile body fluid, excluding blood. Isolates included in this study were from adult patients ( $\geq 18$ years) with IPD between January 2015 and December 2018, with only one isolate from each episode being considered. Isolates were identified as pneumococci by colony morphology on blood agar plates, optochin susceptibility, and bile solubility.

Serotypes were determined by the standard capsular reaction test using the chessboard system and specific sera [13] (Statens Serum Institut, Copenhagen, Denmark). Serotypes were classified into vaccine serotypes, i.e., those included in PCV7 (serotypes 4, 6B, 9V, 14, 18C, 19F, and 23F), PCV13 (all PCV7 serotypes plus 1, 3, 5, 6A, 7F, and 19A, the later also referred to as addPCV13), PCV15 (all PCV13 serotypes plus 22F and 33F, the later also referred to as addPCV15), PCV20 (all PCV15 serotypes plus 8, 10A, 11A, 12F, and 15B, the later also referred to as addPCV20), and PPV23 (all PCV20 serotypes, except serotype 6A, plus serotypes $2,9 \mathrm{~N}, 17 \mathrm{~F}$ and 20, the later also referred to as addPPV23), or as non-vaccine serotypes (NVTs). Given the high frequency of spontaneous switching between serotypes $15 \mathrm{~B}$ and $15 \mathrm{C}$, we decided to group isolates with these serotypes into a single group and to assume that PCV20 and PPV23 protect against both these serotypes [14]. Additionally, given the difficulties in phenotypically distinguishing isolates of serotypes $25 \mathrm{~A}$ and 38 , as well as isolates with serotypes 29 and 35B, these also grouped together into 25A/38 and 29/35B, respectively.

Minimal inhibitory concentrations (MICs) for penicillin and cefotaxime were determined using Etest strips (Biomérieux, Marcy l'Étoile, France). Unless otherwise stated, we used the CLSI-recommended breakpoints for oral penicillin as epidemiological breakpoints that allowed for comparison with previous studies [15]. Isolates were further characterized by determining their susceptibility to erythromycin, clindamycin, vancomycin, 
linezolid, tetracycline, levofloxacin, trimethoprim-sulfamethoxazole, and chloramphenicol by the Kirby-Bauer disk diffusion technique according to the CLSI recommendations and interpretative criteria [15].

Macrolide resistance phenotypes were identified using a double disc test with erythromycin and clindamycin, as previously described [16]. Simultaneous resistance to

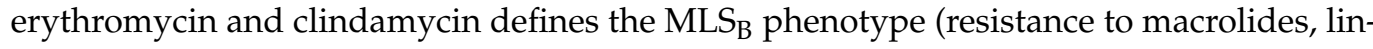
cosamides, and streptogramin B), while non-susceptibility to only erythromycin indicates the M phenotype.

Simpson's index of diversity (SID) and respective 95\% confidence intervals (CI95) were used to measure population diversity [17]. Differences were evaluated by Fisher's exact test, and the Cochran-Armitage test (CA) was used for trends with the false discovery rate (FDR) correction for multiple testing [18]. A $p$-value of $<0.05$ was considered significant for all tests.

\section{Results}

\subsection{Isolate Collection}

Between 2015 and 2018, a total of 2172 isolates responsible for adult IPD were collected in Portugal, distributed as follows: 529 in 2015, 501 in 2016, 576 in 2017, and 566 in 2018. One additional case was identified and directly serotyped by molecular methods from patient CSF in 2015. In most cases, the pneumococcus was identified in blood (93.1\%; $n=2013)$, as well as in the CSF $(5.2 \% ; n=113)$, pleural fluid $(1.3 \% ; n=29)$, peritoneal fluid $(0.5 \% ; n=11)$, synovial fluid $(0.2 \% ; n=5)$, and pericardial fluid $(0.1 \% ; n=2)$. The distribution of the cases among the different age groups was as follows: 397 isolates were recovered from patients aged 18-49 years, 497 were recovered from patients 50-64 years, and 1279 were recovered from older patients ( $\geq 65$ years).

\subsection{Serotype Distribution}

Overall, 58 different serotypes, as well as eight non-typeable (NT) isolates, were identified. The case identified directly from patient CSF could not be resolved to the serotype level having been identified as $22 \mathrm{~F} / 22 \mathrm{~A}$ and being considered an NVT for the purpose of further analysis. The most frequent serotypes were, by decreasing order, serotypes $8(n=413 ; 19 \%), 3(n=334 ; 15 \%), 22 \mathrm{~F}(n=148 ; 7 \%), 14(n=138 ; 6 \%)$, and $19 \mathrm{~A}$ $(n=116 ; 5 \%)$, together accounting for over half of the isolates $(n=1149 ; 53 \%)$. A significant proportion of the isolates still expressed serotypes included in PCV7 $(13 \% ; n=289)$, while over a third of cases were caused by serotypes included in PCV13 $(36 \% ; n=794)$. Serotypes exclusively found in PPV23 were responsible for $44 \%$ of IPD cases $(n=955)$ and $20 \%$ of the isolates $(n=424)$ expressed serotypes not included in any vaccine formulation (NVTs). The numbers of isolates expressing serotypes included in PCVs and in PPV23, stratified by age group, are represented in Figures 1-3. A total of 35 serotypes were found among the $113 \mathrm{CSF}$ isolates, with serotypes $3(n=22) ; 19 \mathrm{~F}(n=8) ; 8(n=8) ; 23 \mathrm{~A}(n=7) ; 22 \mathrm{~F}(n=6) ;$ and $6 \mathrm{C}, 11 \mathrm{~A}$, and $23 \mathrm{~B}(n=5$ each) represented by $\geq 5$ isolates and together accounting for $58 \%$ of all CSF isolates. Out of these, serotypes $19 \mathrm{~F}(p=0.007), 23 \mathrm{~A}(p=0.003)$, and 23B $(p=0.002)$ were associated with isolation from the CSF (all significant after FDR), while serotype 8 $(p=0.001$, which was significant after FDR) was underrepresented among CSF isolates.

Overall serotype diversity was high $(0.920$, CI95 $=0.913-0.926)$, with no differences in SID between the four years included in this study. Serotype diversity was also high among the three age groups, although a difference was noted between isolates recovered in patients aged $18-49$ years $(\mathrm{SID}=0.884 ; \mathrm{CI} 95=0.859-0.908)$ and those aged $\geq 65$ years $(\mathrm{SID}=0.927$; CI95 $=0.920-0.933)(p=0.015)$. Isolates recovered from patients aged 50-64 years had an intermediate SID value between these two: 0.905 (CI95 = 0.888-0.921). 


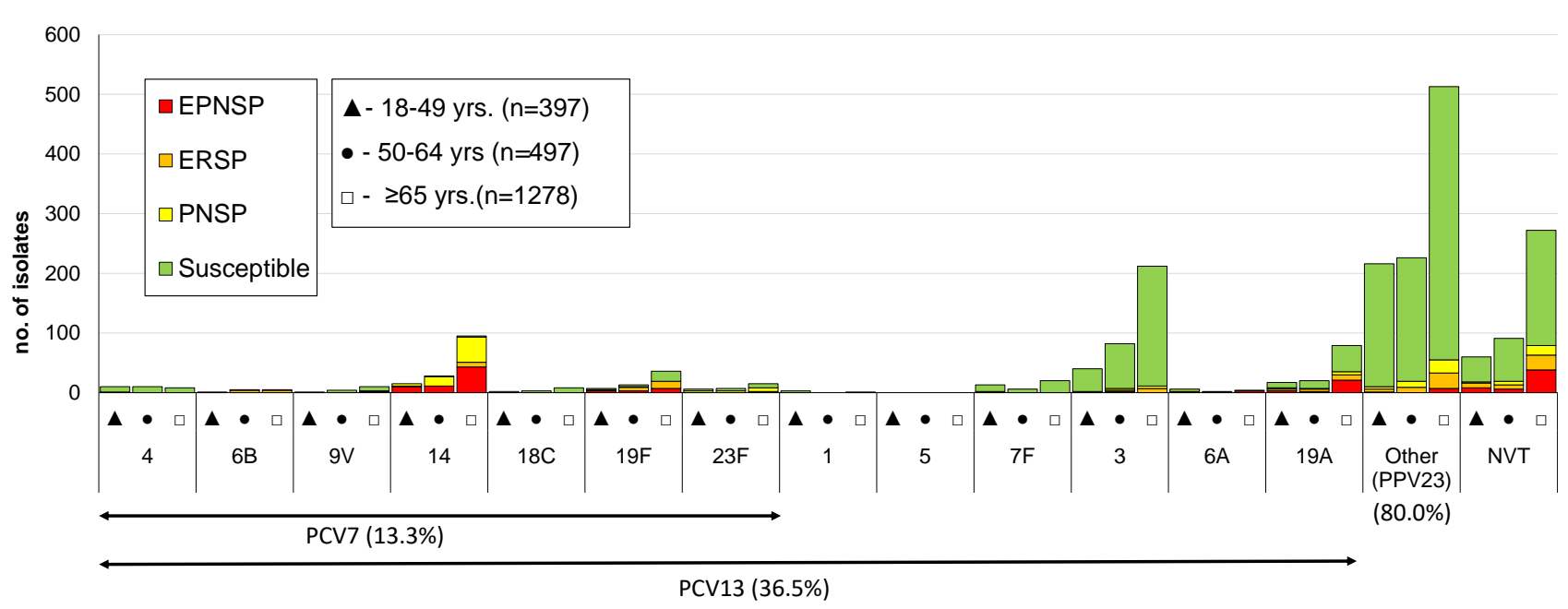

Figure 1. Serotypes of isolates causing invasive pneumococcal disease in adult patients ( $\geq 18$ years) in Portugal from 2015 to 2018. The number of isolates expressing each serotype in each of the considered age groups is indicated. Isolates recovered from patients $18-49,50-64$, and $\geq 65$ years old are indicated by black triangles, black circles, and open squares, respectively. Isolates presenting both erythromycin resistance and penicillin non-susceptibility (EPNSP) are represented by red bars. Erythromycin-resistant pneumococci (ERP) is indicated by orange bars. Penicillin non-susceptible isolates (PNSP) are indicated by yellow bars. Isolates susceptible to both penicillin and erythromycin are represented by green bars. In one case in the $\geq 65$ years age group, the antimicrobial susceptibility was unknown because the diagnosis was made by molecular methods and is not represented in Figure 1. The serotypes included in the 7-valent conjugate vaccine (PCV7) and the 13-valent conjugate vaccine (PCV13) are indicated by the arrows. NVT: non-vaccine serotypes; other: the additional serotypes included in the 23-valent polysaccharide vaccine (PPV23) and not present in PCV13.

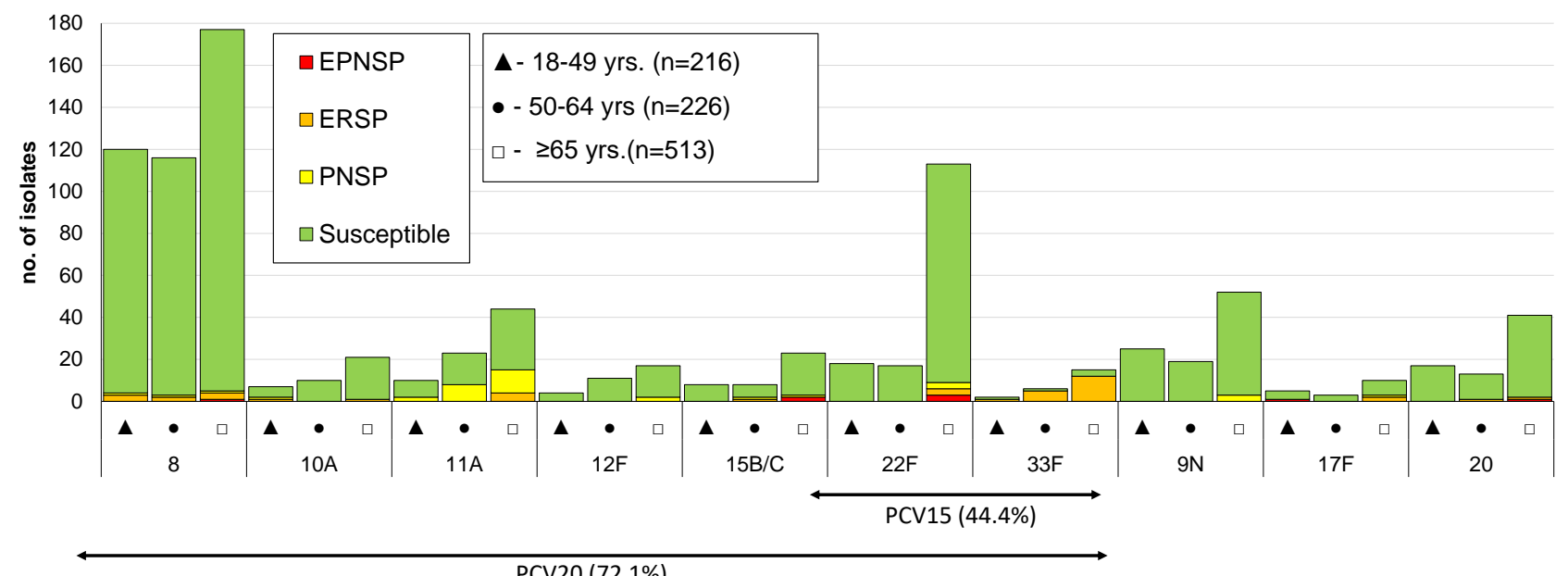

Figure 2. Isolates expressing serotypes present in PPV23 but not included in PCV13 causing invasive pneumococcal disease in adult patients ( $\geq 18$ years) in Portugal from 2015 to 2018. See legend of Figure 1. Out of the 11 serotypes present in PPV23 but absent from PCV13, serotype 2 was not found in our collection.

There were differences in serotype distribution between the age groups. The proportion of isolates expressing the 24 major serotypes ( $n>20$ isolates) in each age group is represented in Table 1. Among these serotypes, some decreased in importance with increasing age group, such as serotype 8 and 4 , while the opposite trend was noted for serotypes 3, 22F, 6C, 14, and 31 (all significant after FDR correction). 


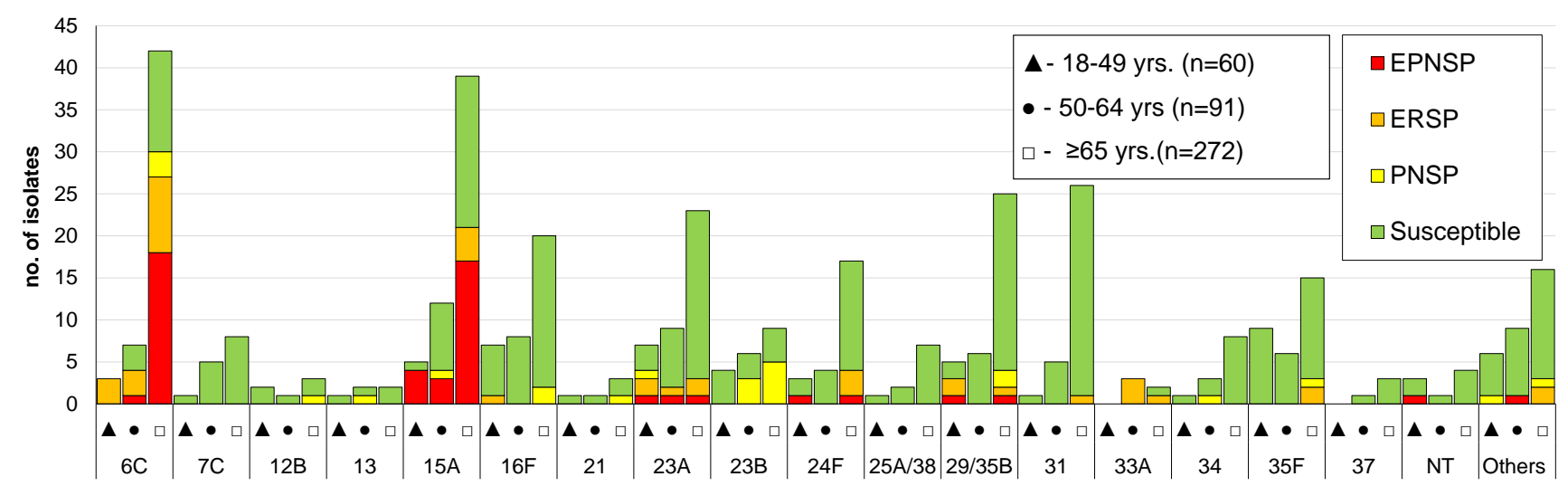

Figure 3. Isolates expressing serotypes not included in any pneumococcal vaccine causing invasive pneumococcal disease in adult patients ( $\geq 18$ years) in Portugal from 2015 to 2018. See legend of Figure 1. NT: non-typable. Isolates expressing serotypes 25A/38 and 29/35B could not be phenotypically distinguished and are represented together. Only serotypes including $n>3$ isolates were discriminated. Others include the following serotypes: 9A, 11D ( $n=3$ each); 6D, 11F, 11C, 12A, 15F, 18A, 22A, and 35A ( $n=2$ each); and 7B, 19B, 19C, 24A, 24B, 28A, 39, and 43 ( $n=1$ each).

During the study period, there were also changes in the proportion of IPD cases caused by vaccine serotypes, as represented in Figure 4. PCV13 serotype IPD decreased from $40.0 \%$ in 2015 to $33.6 \%$ in 2018, mostly driven by a decrease in the proportion of PCV7 serotype IPD, which decreased from $15.5 \%$ in 2015 to $11.3 \%$ in 2018, both of which were significant after FDR correction ( $p=0.01$ and $p=0.02$, respectively). The proportion of IPD caused by isolates expressing addPCV13 serotypes also decreased, though less significantly, from $24.5 \%$ in 2015 to $22.3 \%$ in 2018 . The proportion of PPV23 serotype IPD slightly increased from $78.3 \%$ in 2015 to $81.3 \%$ in 2018 , with the cases caused by the addPCV15, addPCV20, and addPPV23 serotypes considered together increasing from $39.1 \%$ in 2015 to $48.4 \%$ in 2018 ( $p<0.001$, which was significant after FDR correction). The proportion of NVT IPD decreased slightly from $20.9 \%$ in 2015 to $18.0 \%$ in 2018 . The variations in PCV15 serotype IPD closely tracked those of PCV13 serotype IPD, whereas that of PCV20 serotype IPD closely followed that of PPV23 serotype IPD (Figure 4). When also considering the previous study period (2012-2014) in the analysis, the same trends were significant, but, in this case, the decrease in PCV13 serotype IPD was mostly driven by a decrease in the proportion of IPD cases caused by the addPCV13 serotypes from $37.6 \%$ in 2012 to $22.3 \%$ in 2018 ( $p<0.0001$, which was significant after FDR correction).

The evolution of individual serotypes responsible for IPD in adults from 2012 to 2018 is represented in Table 2 for serotypes expressed by $>3$ isolates in at least one of the considered years. In the current study period (2015-2018), the proportion of IPD caused by serotypes 8 and 12F increased from $14.9 \%$ and $0.9 \%$ in 2015 to $22.1 \%$ and $2.7 \%$ in 2018, respectively, both unsupported after FDR correction. The opposite trend was detected for serotypes 7F (from 3\% to $1.2 \%$ ), 19A (from $6.8 \%$ to $2.8 \%$ ), and $6 \mathrm{C}$ (from $3.8 \%$ to $1.8 \%$ ), although none of these were supported after FDR correction. However, when considering data from 2012 to 2018, several significant changes were detected, including an increase in proportion of serotype 8 IPD (from $8.4 \%$ to $22.1 \%$; CA $p<0.001$ ) and serotype 33F IPD (from $0.2 \%$ to $1.6 \%$; CA $p=0.001$ ), as well as decreases in the proportion of serotype 7F (from $8.2 \%$ to $1.2 \%$; CA $p<0.001$ ), 1 (from $3.0 \%$ to $0 \%$; CA $p<0.001$ ), and 19A IPD (from $9.7 \%$ to $2.8 \%$; CA $p<0.001$ ). 
Table 1. Serotype distribution in each age group ( $n>20$ isolates).

\begin{tabular}{|c|c|c|c|c|}
\hline \multirow{2}{*}{ Serotype } & \multicolumn{3}{|c|}{ No of Isolates (\%) } & \multirow{2}{*}{$\mathrm{CA}^{1}$} \\
\hline & 18-49 Years & 50-64 Years & $\geq 65$ Years & \\
\hline 8 & $120(30.2)$ & $116(23.3)$ & $177(13.8)$ & $<0.001$ \\
\hline 3 & $40(10.1)$ & $82(16.5)$ & $212(16.6)$ & 0.005 \\
\hline $22 \mathrm{~F}$ & $18(4.5)$ & $17(3.4)$ & $113(8.8)$ & $<0.001$ \\
\hline 14 & $15(3.8)$ & $28(5.6)$ & $95(7.4)$ & 0.007 \\
\hline $19 \mathrm{~A}$ & $17(4.3)$ & $20(4.0)$ & $79(6.2)$ & 0.068 \\
\hline $9 \mathrm{~N}$ & $25(6.3)$ & $19(3.8)$ & $52(4.1)$ & 0.109 \\
\hline $11 \mathrm{~A}$ & $10(2.5)$ & $23(4.6)$ & $44(3.4)$ & 0.682 \\
\hline 20 & $17(4.3)$ & $13(2.6)$ & $41(3.2)$ & 0.455 \\
\hline $15 \mathrm{~A}$ & $5(1.3)$ & $12(2.4)$ & $39(3.0)$ & 0.050 \\
\hline $19 \mathrm{~F}$ & $7(1.8)$ & $13(2.6)$ & $36(2.8)$ & 0.276 \\
\hline $6 \mathrm{C}$ & $3(0.8)$ & $7(1.4)$ & $42(3.3)$ & 0.001 \\
\hline $7 \mathrm{~F}$ & $13(3.3)$ & $6(1.2)$ & $20(1.6)$ & 0.067 \\
\hline $15 B / C$ & $8(2.0)$ & $8(1.6)$ & $23(1.8)$ & 0.863 \\
\hline $23 \mathrm{~A}$ & $7(1.8)$ & $9(1.8)$ & $23(1.8)$ & 0.972 \\
\hline $10 \mathrm{~A}$ & $7(1.8)$ & $10(2.0)$ & $21(1.6)$ & 0.765 \\
\hline $16 \mathrm{~F}$ & $7(1.8)$ & $8(1.6)$ & $20(1.6)$ & 0.792 \\
\hline $29 / 35 B$ & $3(0.8)$ & $5(1.0)$ & $25(2.0)$ & 0.053 \\
\hline 31 & $1(0.3)$ & $5(1.0)$ & $26(2.0)$ & 0.006 \\
\hline $12 \mathrm{~F}$ & $4(1.0)$ & $11(2.2)$ & 17 (1.3) & 0.998 \\
\hline $35 \mathrm{~F}$ & $9(2.3)$ & $6(1.2)$ & $15(1.2)$ & 0.145 \\
\hline 4 & $10(2.5)$ & $10(2.0)$ & $8(0.6)$ & 0.001 \\
\hline $23 \mathrm{~F}$ & $6(1.5)$ & $7(1.4)$ & $15(1.2)$ & 0.564 \\
\hline $24 \mathrm{~F}$ & $3(0.8)$ & $4(0.8)$ & 17 (1.3) & 0.262 \\
\hline $33 \mathrm{~F}$ & $2(0.5)$ & $6(1.2)$ & $15(1.2)$ & 0.324 \\
\hline
\end{tabular}

${ }^{1}$ CA: Cochran-Armitage test for trend. In bold are the serotypes with significant $p$-values $(p<0.05)$ after FDR correction.

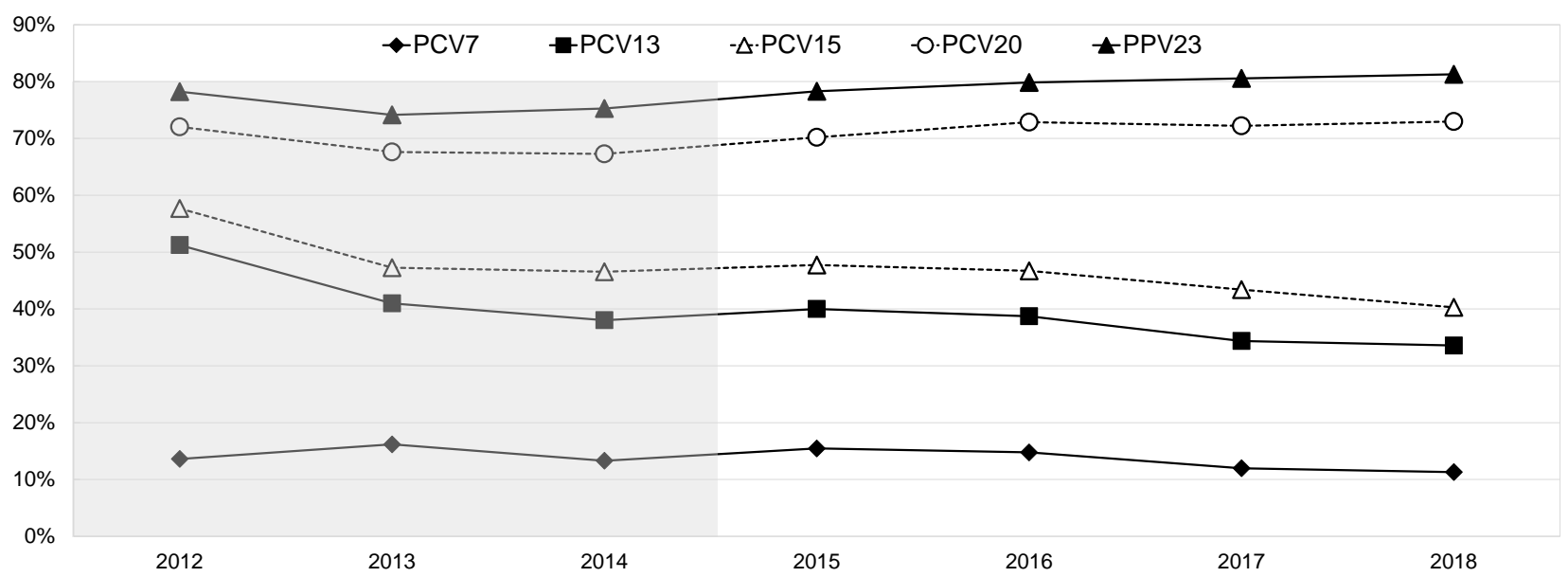

Figure 4. Proportion of isolates expressing serotypes included in existing and future pneumococcal vaccines causing invasive pneumococcal disease in adult patients ( $\geq 18$ years) in Portugal from 2012 to 2018. The data up to 2014 were presented previously [1]. See text for the serotypes included in each of the vaccines. 
Table 2. Serotypes of the isolates responsible for invasive pneumococcal disease in adult patients ( $\geq 18$ years) from 2012 to 2018 .

\begin{tabular}{|c|c|c|c|c|c|c|c|c|c|}
\hline \multirow{3}{*}{ Serotype $^{1}$} & \multicolumn{7}{|c|}{ No. of Isolates (\%) } & \multirow{3}{*}{$\begin{array}{c}\mathrm{CA}^{2} \\
2015-2018\end{array}$} & \multirow{3}{*}{$\begin{array}{c}\mathrm{CA}^{2} \\
2012-2018\end{array}$} \\
\hline & \multirow[b]{2}{*}{2012} & \multicolumn{6}{|c|}{ Current Study Period } & & \\
\hline & & 2013 & 2014 & 2015 & 2016 & 2017 & 2018 & & \\
\hline \multicolumn{10}{|l|}{ PCV13 } \\
\hline 1 & $12(3.0)$ & $7(1.8)$ & $7(1.9)$ & $2(0.4)$ & $2(0.4)$ & $0(0.0)$ & $0(0.0)$ & 0.063 & $<0.001$ \\
\hline 3 & $66(16.3)$ & $45(11.7)$ & $50(13.3)$ & $72(13.6)$ & $79(15.8)$ & $84(14.6)$ & $99(17.5)$ & 0.125 & 0.154 \\
\hline 4 & $6(1.5)$ & $8(2.1)$ & $9(2.4)$ & $7(1.3)$ & $8(1.6)$ & $8(1.4)$ & $5(0.9)$ & 0.478 & 0.171 \\
\hline $6 \mathrm{~A}$ & $2(0.5)$ & $1(0.3)$ & $4(1.1)$ & $4(0.8)$ & $3(0.6)$ & $1(0.2)$ & $4(0.7)$ & 0.698 & 0.937 \\
\hline $6 \mathrm{~B}$ & $5(1.2)$ & $5(1.3)$ & $5(1.3)$ & $3(0.6)$ & $1(0.2)$ & $6(1.0)$ & $1(0.2)$ & 0.795 & 0.031 \\
\hline $7 \mathrm{~F}$ & $33(8.2)$ & $18(4.7)$ & $10(2.7)$ & $16(3.0)$ & $9(1.8)$ & $7(1.2)$ & $7(1.2)$ & 0.020 & $<0.001$ \\
\hline $9 \mathrm{~V}$ & $4(1.0)$ & $4(1.0)$ & $1(0.3)$ & $7(1.3)$ & $1(0.2)$ & $3(0.5)$ & $4(0.7)$ & 0.340 & 0.344 \\
\hline 14 & $29(7.2)$ & $26(6.8)$ & $18(4.8)$ & $39(7.4)$ & $41(8.2)$ & $31(5.4)$ & $27(4.8)$ & 0.024 & 0.196 \\
\hline $18 \mathrm{C}$ & $1(0.2)$ & $4(1.0)$ & $2(0.5)$ & $3(0.6)$ & $3(0.6)$ & $5(0.9)$ & $2(0.4)$ & 0.795 & 0.998 \\
\hline $19 \mathrm{~A}$ & $39(9.7)$ & $24(6.3)$ & $21(5.6)$ & $36(6.8)$ & $27(5.4)$ & $37(6.4)$ & $16(2.8)$ & 0.011 & $<0.001$ \\
\hline $19 \mathrm{~F}$ & $9(2.2)$ & $12(3.1)$ & $6(1.6)$ & $17(3.2)$ & $12(2.4)$ & $12(2.1)$ & $15(2.7)$ & 0.518 & 0.964 \\
\hline $23 \mathrm{~F}$ & $1(0.2)$ & $3(0.8)$ & $9(2.4)$ & $6(1.1)$ & $8(1.6)$ & $4(0.7)$ & $10(1.8)$ & 0.632 & 0.213 \\
\hline \multicolumn{10}{|l|}{ addPPV23 } \\
\hline 8 & $34(8.4)$ & $43(11.2)$ & $46(12.2)$ & $79(14.9)$ & $92(18.4)$ & 117 (20.3) & $125(22.1)$ & 0.002 & $<0.001$ \\
\hline $9 \mathrm{~N}$ & $8(2.0)$ & $13(3.4)$ & $18(4.8)$ & $24(4.5)$ & $19(3.8)$ & $23(4.0)$ & $30(5.3)$ & 0.455 & 0.039 \\
\hline $10 \mathrm{~A}$ & $2(0.5)$ & $8(2.1)$ & $8(2.1)$ & $9(1.7)$ & $11(2.2)$ & $8(1.4)$ & $10(1.8)$ & 0.815 & 0.486 \\
\hline $11 \mathrm{~A}$ & $16(4.0)$ & $18(4.7)$ & $15(4.0)$ & $19(3.6)$ & $17(3.4)$ & $14(2.4)$ & $27(4.8)$ & 0.453 & 0.626 \\
\hline $12 \mathrm{~F}$ & $6(1.5)$ & $8(2.1)$ & $4(1.1)$ & $5(0.9)$ & $3(0.6)$ & $9(1.6)$ & $15(2.7)$ & 0.008 & 0.349 \\
\hline $15 B / C$ & $5(1.2)$ & $9(2.3)$ & $8(2.1)$ & 7 (1.3) & $8(1.6)$ & $16(2.8)$ & $8(1.4)$ & 0.578 & 0.756 \\
\hline $17 \mathrm{~F}$ & $5(1.2)$ & $2(0.5)$ & $2(0.5)$ & $5(0.9)$ & $2(0.4)$ & $3(0.5)$ & $8(1.4)$ & 0.371 & 0.775 \\
\hline 20 & $14(3.5)$ & $11(2.9)$ & $14(3.7)$ & $18(3.4)$ & $17(3.4)$ & $23(4.0)$ & $13(2.3)$ & 0.420 & 0.665 \\
\hline $22 \mathrm{~F}$ & $25(6.2)$ & $23(6.0)$ & $31(8.2)$ & $40(7.5)$ & $34(6.8)$ & $45(7.8)$ & $29(5.1)$ & 0.191 & 0.759 \\
\hline $33 \mathrm{~F}$ & $1(0.2)$ & $1(0.3)$ & $1(0.3)$ & $1(0.2)$ & $6(1.2)$ & $7(1.2)$ & $9(1.6)$ & 0.031 & 0.001 \\
\hline \multicolumn{10}{|l|}{ NVT } \\
\hline $6 C$ & $8(2.0)$ & $14(3.7)$ & $6(1.6)$ & $20(3.8)$ & $14(2.8)$ & $8(1.4)$ & $10(1.8)$ & 0.011 & 0.212 \\
\hline $7 C$ & $1(0.2)$ & $4(1.0)$ & $1(0.3)$ & $2(0.4)$ & $2(0.4)$ & $5(0.9)$ & $5(0.9)$ & 0.196 & 0.308 \\
\hline $15 \mathrm{~A}$ & $3(0.7)$ & $11(2.9)$ & $13(3.5)$ & $12(2.3)$ & $14(2.8)$ & $14(2.4)$ & $16(2.8)$ & 0.660 & 0.235 \\
\hline $16 \mathrm{~F}$ & $13(3.2)$ & $3(0.8)$ & $7(1.9)$ & $11(2.1)$ & $8(1.6)$ & $13(2.3)$ & $3(0.5)$ & 0.095 & 0.079 \\
\hline $23 \mathrm{~A}$ & $9(2.2)$ & $8(2.1)$ & $9(2.4)$ & $13(2.5)$ & $7(1.4)$ & $12(2.1)$ & $7(1.2)$ & 0.161 & 0.159 \\
\hline $23 \mathrm{~B}$ & $4(1.0)$ & $5(1.3)$ & $3(0.8)$ & $6(1.1)$ & $3(0.6)$ & $4(0.7)$ & $6(1.1)$ & 0.951 & 0.632 \\
\hline $24 \mathrm{~F}$ & $5(1.2)$ & $9(2.3)$ & $9(2.4)$ & $7(1.3)$ & $7(1.4)$ & $5(0.9)$ & $5(0.9)$ & 0.359 & 0.075 \\
\hline $25 \mathrm{~A} / 38$ & $3(0.7)$ & $3(0.8)$ & $2(0.5)$ & $1(0.2)$ & $3(0.6)$ & $5(0.9)$ & $1(0.2)$ & 0.870 & 0.448 \\
\hline $29 / 35 B$ & $10(2.5)$ & $6(1.6)$ & $10(2.7)$ & $6(1.1)$ & $7(1.4)$ & $14(2.4)$ & $10(1.8)$ & 0.241 & 0.709 \\
\hline 31 & $5(1.2)$ & $2(0.5)$ & $4(1.1)$ & $6(1.1)$ & $10(2.0)$ & $9(1.6)$ & $7(1.2)$ & 0.956 & 0.309 \\
\hline $33 \mathrm{~A}$ & $2(0.5)$ & $5(1.3)$ & $2(0.5)$ & $4(0.8)$ & $0(0.0)$ & $0(0.0)$ & $1(0.2)$ & 0.060 & 0.010 \\
\hline 34 & $3(0.7)$ & $1(0.3)$ & $4(1.1)$ & $5(0.9)$ & $3(0.6)$ & $1(0.2)$ & $3(0.5)$ & 0.245 & 0.431 \\
\hline $35 \mathrm{~F}$ & $7(1.7)$ & $4(1.0)$ & $2(0.5)$ & $5(0.9)$ & $11(2.2)$ & $6(1.0)$ & $8(1.4)$ & 0.904 & 0.808 \\
\hline NT & $1(0.2)$ & $3(0.8)$ & $6(1.6)$ & $2(0.4)$ & $1(0.2)$ & $3(0.5)$ & $2(0.4)$ & 0.834 & 0.380 \\
\hline Other & $7(1.7)$ & $12(3.1)$ & $9(2.4)$ & $11(2.1)$ & $8(1.6)$ & $14(2.4)$ & $18(3.2)$ & & \\
\hline Total & 404 & 383 & 376 & 530 & 501 & 576 & 566 & - & - \\
\hline
\end{tabular}

${ }^{1}$ Only serotypes detected in $>3$ isolates in at least one year are shown; the remaining are represented in "others." PCV13: serotypes included in PCV13; addPPV13: the additional serotypes included in PPV23 that are not present in PCV13; NVT: non-vaccine types. 2 CA: Cochran-Armitage test for trend. In bold are the serotypes with significant $p$-values $(p<0.05)$ after FDR correction.

The distribution of IPD cases over the study period stratified by age group is represented in Table 3. PCV7 serotypes decreased in patients $\geq 50$ years, but this was not supported after FDR correction. The addPCV15 serotypes declined in the 18-49 year-old patients but remained stable in older patients. The addPCV20 serotypes increased in all age groups, but this was only supported after FDR correction in the $\geq 65$ years patients. Both the addPPV23 serotypes and the NVTs varied without a consistent trend. 
Table 3. Number of isolates responsible for invasive pneumococcal disease in adult patients, according to vaccine serotype groups and age groups, from 2015 to 2018.

\begin{tabular}{ccccccc}
\hline $\begin{array}{c}\text { Age Group } \\
\text { (Years) }\end{array}$ & $\begin{array}{l}\text { Serotype } \\
\text { Group }\end{array}$ & $\mathbf{2 0 1 5}$ & $\mathbf{2 0 1 6}$ & $\mathbf{2 0 1 7}$ & $\mathbf{2 0 1 8}$ & CA $^{2}$ \\
\hline $18-49$ & PCV7 & $8(7.8)$ & $14(16.5)$ & $12(10.9)$ & $8(8.1)$ & 0.807 \\
& addPCV13 & $23(22.3)$ & $19(22.4)$ & $15(13.6)$ & $22(22.2)$ & 0.593 \\
& addPCV15 & $13(12.6)$ & $3(3.5)$ & $4(3.6)$ & $0(0)$ & $<\mathbf{0 . 0 0 1}$ \\
& addPCV20 & $35(34.0)$ & $28(32.9)$ & $44(40.0)$ & $42(42.4)$ & 0.139 \\
& addPPV23 & $11(10.7)$ & $8(9.4)$ & $13(11.8)$ & $15(15.2)$ & 0.286 \\
& NVT & $13(12.6)$ & $13(15.3)$ & $22(20.0)$ & $12(12.1)$ & 0.802 \\
$50-64$ & PCV7 & $21(16.9)$ & $16(14.0)$ & $18(14.4)$ & $15(11.2)$ & 0.216 \\
& addPCV13 & $33(26.6)$ & $26(22.8)$ & $24(19.2)$ & $27(20.1)$ & 0.166 \\
& addPCV15 & $2(1.6)$ & $7(6.1)$ & $7(5.6)$ & $7(5.2)$ & 0.218 \\
& addPCV20 & $30(24.2)$ & $44(38.6)$ & $44(35.2)$ & $51(38.1)$ & 0.041 \\
& addPPV23 & $13(10.5)$ & $3(2.6)$ & $6(4.8)$ & $13(9.7)$ & 0.993 \\
& NVT & $25(20.2)$ & $18(15.8)$ & $26(20.8)$ & $21(15.7)$ & 0.558 \\
& PCV7 & $53(17.5)$ & $44(14.6)$ & $39(11.4)$ & $41(12.3)$ & 0.033 \\
& addPCV13 & $74(24.4)$ & $75(24.8)$ & $90(26.4)$ & $77(23.1)$ & 0.819 \\
& addPCV15 & $26(8.6)$ & $30(9.9)$ & $41(12.0)$ & $31(9.3)$ & 0.584 \\
& addPCV20 & $54(17.8)$ & $59(19.5)$ & $78(22.9)$ & $92(27.6)$ & $\mathbf{0 . 0 0 2}$ \\
& addPPV23 & $23(7.6)$ & $27(8.9)$ & $30(8.8)$ & $23(6.9)$ & 0.733 \\
& NVT & $73(24.1)$ & $67(22.2)$ & $63(18.5)$ & $69(20.7)$ & 0.183 \\
\hline
\end{tabular}

${ }^{1}$ PCV7: serotypes included in the 7-valent conjugate vaccine; addPCV13: additional serotypes included in the 13-valent conjugate vaccine and not present in PCV7-1, 3, 5, 6A, 7F, and 19A; addPCV15: additional serotypes included in the 15-valent conjugate vaccine and not present in PCV13-22F and 33F; addPCV20: additional serotypes included in the 20-valent conjugate vaccine and not present in PCV15-8, 10A, 11A, 12F, and 15B (for the purpose of this paper, we assumed that protection was afforded against IPD by the 15B/C group of isolates); addPPV23: the additional 3 serotypes exclusively present in the 23-valent pneumococcal polysaccharide vaccine-9N, 17F and 20; NVT: serotypes not included in any of the currently available pneumococcal vaccines.

${ }^{2}$ CA: Cochran-Armitage test for trend. Values in bold were significant after FDR correction.

\subsection{Antimicrobial Susceptibility}

Resistance to all antimicrobials tested is summarized in Table 4. Among the collection, 326 isolates $(15.0 \%)$ were classified as penicillin non-susceptible pneumococci (PNSP), of which $94.8 \%(n=309)$ presented low level resistance and 5.2\% $(n=17)$ presented high level resistance. Considering current CLSI breakpoints for parenteral penicillin, 19 out of 112 CSF isolates would have been considered resistant $(17.0 \%)$, and only $0.2 \%(n=6)$ nonCSF isolates would have been considered intermediately resistant. Erythromycin resistance was expressed by 322 isolates $(14.8 \%)$, of which the majority $(n=275 ; 85.4 \%)$ presented the MLS $_{\mathrm{B}}$ phenotype and $14.6 \%(n=47)$ presented the M phenotype. Simultaneous nonsusceptibility to penicillin and erythromycin (EPNSP) accounted for $7.9 \%$ of the isolates $(n=172)$. Throughout the study period, resistance to erythromycin significantly decreased from $18.5 \%$ in 2015 to $10.8 \%$ in 2018, and clindamycin resistance decreased from $15.5 \%$ in 2015 to $9.9 \%$ in 2018 (CA $p<0.001$ for both). Penicillin, erythromycin, and clindamycin resistance was mostly associated with the $\geq 65$ years group (CA $p=0.002, p=0.01$, and $p=0.007$, respectively). 
Table 4. Number of isolates responsible for invasive pneumococcal disease in adult patients, according to vaccine serotype groups and age groups, from 2015 to 2018.

\begin{tabular}{|c|c|c|c|}
\hline \multirow[b]{2}{*}{ Antimicrobial ${ }^{1}$} & \multicolumn{3}{|c|}{ No. Resistant Isolates (\%) } \\
\hline & 18-49 Years $(n=397)$ & 50-64 Years $(n=497)$ & $\geq 65$ Years $(n=1278)^{2}$ \\
\hline PEN & $44(11.1)$ & $65(13.8)$ & $217(17.0)$ \\
\hline $\operatorname{MIC}^{3}{ }^{3}$ & 0.016 & 0.125 & 0.5 \\
\hline $\mathrm{MIC} 0^{3}$ & 0.012 & 0.012 & 0.012 \\
\hline CTX & $1(0.3)$ & $2(0.4)$ & $3(0.2)$ \\
\hline $\operatorname{MIC}^{3} 0^{3}$ & 0.016 & 0.125 & 0.38 \\
\hline $\mathrm{MIC} 0^{3}$ & 0.016 & 0.016 & 0.016 \\
\hline LEV & $2(0.5)$ & $2(0.4)$ & $9(0.7)$ \\
\hline ERY & $51(12.8)$ & $57(11.5)$ & $214(16.7)$ \\
\hline CLI & $41(10.3)$ & $49(9.9)$ & $185(14.5)$ \\
\hline $\mathrm{CHL}$ & $5(1.3)$ & $12(2.4)$ & $23(1.8)$ \\
\hline SXT & $47(11.8)$ & $62(12.5)$ & $175(13.7)$ \\
\hline TET & $53(13.4)$ & $79(15.9)$ & $214(16.7)$ \\
\hline
\end{tabular}

${ }^{1}$ PEN: penicillin; CTX: cefotaxime; LEV: levofloxacin; ERY: erythromycin; CLI: clindamycin; CHL: chloramphenicol; SXT: trimethoprim/sulfamethoxazole; TET: tetracycline. All isolates were susceptible to vancomycin and linezolid. ${ }^{2}$ In this age group, it was not possible to determine the antimicrobial resistance in the case where the diagnosis was made by molecular methods. ${ }^{3}$ The minimal inhibitory concentration values of $50 \%$ or $90 \%$ of the isolates are shown in $\mathrm{mg} / \mathrm{L}$.

The proportion of resistant isolates among each serotype is illustrated in Figures 1-3. The most frequent serotypes $(n>20)$ among penicillin non-susceptible isolates were serotypes 14,19A, 15A, 6C, and 11A (by decreasing order of frequency), together accounting for $74.2 \%(n=242)$ of the isolates. Serotypes $14,19 \mathrm{~A}, 6 \mathrm{C}, 19 \mathrm{~F}$, and $15 \mathrm{~A}$ were, by decreasing order of frequency, the most frequent $(n>20)$ among erythromycin-resistant isolates, together accounting for $65.2 \%(n=210)$ of the isolates. PCV7 serotypes accounted for $51.3 \%$ of PNSP, $27.3 \%$ of ERP, and $45.3 \%$ of EPNSP (Figure 1), while PCV13 serotypes accounted for $61.0 \%, 46.7 \%$, and $65.1 \%$ for PNSP, ERP, and EPNSP, respectively (Figure 2). Among EPNSP isolates, a considerable proportion expressed NVT (30.2\%), and among ERP and PNSP isolates, $26.7 \%$ and $15.6 \%$, respectively, expressed NVT. The most frequent NVT among PNSP isolates were $6 \mathrm{C}, 15 \mathrm{~A}, 23 \mathrm{~A}$, and 23B, together accounting for $8 \%$ of PNSP, $16 \%$ of ERP, and $27 \%$ of EPNSP (Figure 3 ).

\section{Discussion}

It is well established that vaccinating children leads to a decrease of vaccine-type IPD in adults through herd immunity $[19,20]$. This is thought to be related to the proportion of vaccinated children [19], so the increase in uptake anticipated from the introduction of PCV13 in the NIP in Portugal was expected to result in further effects in adult IPD. Moreover, the emergence of NVT disease could further influence the serotypes in IPD and even partially erode the benefits of the herd effect of vaccination on the overall burden of disease [20,21].

The decrease of PCV7 serotypes, felt since a few years after PCV7 introduction [1,2], continued to occur but at a very slow pace and with all PCV7 serotypes still being present as causes of IPD in 2018. In contrast, the decrease of the addPCV13 serotypes was underpinned by serotypes 1 and 5, which were not found among IPD cases in the last years of the study, and decreases in serotypes 7F and 19A. In fact, the decrease in addPCV13 serotypes was not more pronounced due to an increase in serotype 3 IPD. Significant increases in the incidence of serotype 3 IPD were also seen in France and England in recent years [21,22]. In fact, the leading serotypes causing adult IPD in Portugal in 2015-2018 were similar to those found in other European countries [4,21-23], although their rank order could be different. Among the PCV serotypes, serotype 3 was always found to be a leading cause of adult IPD in Europe in recent years, together with serotypes 19A and 7F [4,21-23], although the latter two have frequently been found to be decreasing of late, as seen in Portugal. Serotype 14 persists in Portugal and Spain [4,23] but is less frequent elsewhere [21,22]. Among 
the serotypes not included in any PCV, serotype 8 is consistently found among the three leading causes of adult IPD, if not the most prevalent, while serotypes $9 \mathrm{~N}, 12 \mathrm{~F}$ and $22 \mathrm{~F}$ are also leading causes of IPD, albeit with a more variable rank order [4,21-23]. For instance, serotype $12 \mathrm{~F}$ is one of the three most prevalent serotypes in Spain and England [4,22,23], but it is much less frequent in Portugal and France [21]. Among the other non-PCV serotypes responsible for $>2 \%$ of adult IPD in Portugal in 2015-2018-11A, 20, 15A, and 6C - most were also recently found to be important causes of adult IPD in Spain [4,23], and serotype 15A was also important in France and England [21,22], but serotype 20 was not a significant cause of disease in any of these countries. Though we have considered serotype 6C an NVT, cross-protection from the 6A and 6B components in PCV13 has been suggested, leading to a future potential reduction of this serotype despite its current persistence as a cause of adult IPD in several countries. In Ontario, Canada, IPD was found to have a similar serotype distribution to that of these European countries, with a smaller share of serotype 8 IPD [24]. In Argentina, five serotypes are responsible for over 5\% of all adult IPD: 3 , $8,12 \mathrm{~F}, 7 \mathrm{~F}$, and 1 [25]. Most of these are also among the most frequent in Europe, but, in contrast to Argentina, serotype 1 has greatly decreased or is even absent from adult IPD in European countries. Taken together, these results suggest that a similar set of serotypes is emerging in most countries using PCV13 in children as the leading causes of adult IPD, albeit with some notable regional differences in the persistence of PCV13 serotypes and the prevalence of some emerging serotypes. In contrast to the relative homogeneity among these countries, a recent regional study from Japan did not find any case of serotype 8 or 9N IPD [26]. Another prominent difference is the USA, where no increases in non-PCV13 serotype IPD were evident in either children $<5$ years or adults $\geq 65$ years and serotypes $8,9 \mathrm{~N}, 12 \mathrm{~F}$, and 15A were found to be responsible for a minority of IPD [27]. The reasons behind these differences continue to be a matter of debate [27].

Similarly to what was found in England [22], serotype 3 IPD in Portugal was associated with older age. This was also the case for serotypes 14, 22F, and 31 IPD. The increased importance of IPD by these serotypes with age could be associated with infections in adults with underlying conditions, whose proportion also increases with age [28], but our study was not designed to address this. The increased case fatality rate of serotype 3 IPD reported in England [22] and its increased prevalence in older-aged adults could also be partly responsible for the increasing mortality of pneumonia with age in Portugal [28].

Despite two decades of PCV7 use in children, PCV7 serotypes are still present as causes of IPD in adults, and their demise has not accelerated after four years of the introduction of PCV13 in the NIP with an uptake $>95 \%$. Serotypes 14 and 19F (both PCV7 serotypes) are among the leading antimicrobial-resistant serotypes, suggesting that antimicrobial use could partly counter the selective force imposed by vaccination and justify their persistence. The proportion of IPD caused by PCV13 serotypes did decrease after introduction in the NIP but seems to have stabilized in the two most recent years, as in other European countries [20]. The future PCV15 vaccine covers and additional $8 \%$ of adult IPD relative to PCV13, and PCV20 covers an additional $28 \%$ relative to PCV15 (only 8\% less than PPV23). The changes in the potential coverage of PCV20 and PPV23 varied in parallel, attesting to the relevance of the addPCV20 serotypes, which increased in importance in the $\geq 65$ years group during the study period. The large proportion of vaccine-preventable disease in Portugal highlights the potential benefits of increasing the uptake of pneumococcal vaccines in adults, with the forthcoming PCV15 and, particularly, PCV20 vaccines broadening the potential coverage by PCVs and being welcome additions to the prevention of pneumococcal disease.

The average number of isolates from adult IPD sent to us per year in this study period $(n=543)$ substantially increased when compared to 2008-2014 $(n=405)$ [1]. Though this could have been due to increases in adult IPD, as reported elsewhere [21], it could also have been influenced by increased reporting. Consistent with the latter idea, there were no differences in the proportion of isolates of each age group between the two periods. Since our study was not population-based, we could not further clarify this point. 
Our study had several limitations. Our surveillance was not population-based, and it was not designed to estimate the incidence of IPD because it was an exclusively laboratory surveillance and lacked compliance audits. A survey of hospitalized pneumonia cases among adults in Portugal in 2015 found that 1328 had pneumococcal etiology [28]. Considering that most cases of IPD are from invasive pneumonia (e.g., 70\% of cases in the recent report from England [22]) and that invasive pneumonia is $\approx 10 \%$ of all pneumonia cases, the 530 isolates we received in 2015 represent a very high fraction of all adult IPD cases in Portugal. The stability of our surveillance network and its active nature are consistent with the identification of most IPD cases, as suggested by the available data for 2015, so we expect our sample to be representative of Portugal. The study was also not designed to collect information that is important to evaluate the severity of the infections caused by the different serotypes (e.g., hospitalization, ICU admission, and 30-day mortality) or relevant patient information (e.g., vaccination and comorbidities), which would have been important to better understand the changes in IPD accompanying the described serotype dynamics and the potential benefits of the currently used vaccines.

\section{Conclusions}

Despite the introduction of PCV13 in the NIP for children four years ago, the reduction in the PVC13 serotype adult IPD was modest and seems to have stabilized. At best, the herd effect may cause an ongoing slow decrease of addPCV13 serotype IPD like what we saw for the PCV7 serotypes, with almost two decades of use of PCVs targeting these serotypes with an uptake $>60 \%$. This would mean that a substantial fraction of potentially vaccine-preventable disease would continue to occur in the coming years. The advent of new PCVs with a higher valency (PCV15 and PCV20), together with PPV23, affords new opportunities to prevent IPD in adults. An increase in vaccine uptake in adults could potentially lead to important reductions in the $12 \%$ mortality estimated for pneumococcal pneumonia requiring hospitalization in Portugal in 2015 [28].

Author Contributions: Conceptualization, J.M.-C., C.S.-C. and M.R.; methodology, J.M.-C., C.S.-C. and M.R.; formal analysis, J.M.-C., C.S.-C. and M.R.; investigation, C.S.-C., J.G.-S. and I.T.; resources, the Portuguese Group for the Study of Streptococcal Infections; data curation, C.S.-C. and J.G.-S.; writing—original draft preparation, C.S.-C.; writing—review and editing, J.M.-C., C.S.-C. and M.R.; visualization C.S.-C. and M.R.; supervision, J.M.-C., C.S.-C. and M.R.; project administration, J.M.-C. and M.R.; funding acquisition, J.M.-C. All authors have read and agreed to the published version of the manuscript.

Funding: This research was funded partly by Fundação para a Ciência e a Tecnologia, Portugal (PTDC/DTP-EPI/1555/2014), and an unrestricted Investigator initiated project from Pfizer.

Institutional Review Board Statement: The study was conducted according to the guidelines of the Declaration of Helsinki, and approved by the Institutional Review Board (137/13, 15 May 2013). The Centro Académico de Medicina de Lisboa.

Informed Consent Statement: These were considered surveillance activities and were exempt from informed consent.

Data Availability Statement: All the data in this study is available in the figures and tables of the paper.

Acknowledgments: Portuguese Group for the Study of Streptococcal Infections. Margarida Pinto ${ }^{2}$, João Marques ${ }^{2}$, Isabel Peres ${ }^{2}$, Teresa Pina ${ }^{2}$, Isabel Lourenço ${ }^{2}$, Teresa Ferreira ${ }^{2}$, Cristina Marcelo ${ }^{2}$, Isabel Daniel ${ }^{2}$, Odete Chantre ${ }^{2}$, Teresa Vaz ${ }^{3}$, Marília Gião ${ }^{3}$, Rui Ferreira ${ }^{3}$, Rui Tomé Ribeiro ${ }^{3}$, Celeste Pontes $^{3}$, Luísa Boaventura ${ }^{3}$, Catarina Chaves $^{3}$, Teresa Reis ${ }^{3}$, Henrique Oliveira $^{5}$, Ana Cristina Silva ${ }^{6}$, Hermínia Costa $^{6}$, Maria Fátima Silva ${ }^{6}$, Maria Amélia Afonso ${ }^{6}$, Natália Novais ${ }^{7}$, Isabel Brito ${ }^{7}$, Luís Marques Lito ${ }^{8}$, Ana Bruschy Fonseca ${ }^{8}$, Filomena Martins ${ }^{9}$, Maria Ana Pessanha ${ }^{9}$, Elsa Gonçalves ${ }^{9}$, Teresa Morais ${ }^{9}$, Cristina Toscano ${ }^{9}$, Paulo Lopes ${ }^{10}$, Angelina Lameirão ${ }^{10}$, Gabriela Abreu ${ }^{10}$, Aurélia Selaru $^{10}$, Ana Paula Mota Vieira ${ }^{11}$, Margarida Tomaz ${ }^{11}$, Rosa Bento ${ }^{12}$, Maria Helena Ramos ${ }^{13}$, Ana Paula Castro ${ }^{13}$, Fernando Fonseca ${ }^{14}$, Ana Paula Castro ${ }^{15}$, Nuno Canhoto ${ }^{17}$, Teresa Afonso ${ }^{17}$, Ilse Fontes $^{19}$, Paulo Martinho ${ }^{19}$, Ana Domingos ${ }^{20}$, Gina Marrão ${ }^{20}$, José Grossinho ${ }^{20}$, Manuela Ribeiro ${ }^{21}$, 
Helena Gonçalves ${ }^{21}$, Alberta Faustino ${ }^{22}$, Maria Cármen Iglesias ${ }^{22}$, Maria Paula Pinheiro ${ }^{23}$, Rui Semedo $^{23}$, Adriana Coutinho ${ }^{24}$, Luísa Gonçalves ${ }^{25}$, Olga Neto ${ }^{25}$, Luísa Sancho ${ }^{26}$, José Diogo ${ }^{27}$, Ana Rodrigues $^{27}$, Isabel Nascimento ${ }^{27}$, Elmano Ramalheira ${ }^{28}$, Raquel Diaz ${ }^{28}$, Sónia Ferreia ${ }^{28}$, Inês Cravo Roxo $^{28}$, Isabel Vale ${ }^{29}$, Ana Carvalho ${ }^{29}$, José Miguel Ribeiro ${ }^{29}$, Maria Antónia Read ${ }^{30}$, Valquíria Alves $^{30}$, Margarida Monteiro ${ }^{30}$, Margarida Rodrigues ${ }^{32}$, José Mota Freitas ${ }^{33}$, Sandra Vieira ${ }^{33}$, Elsa Calado $^{34}$, Paula Pinto ${ }^{34}$, Maria Favila Meneses ${ }^{34}$, José Germano de Sousa ${ }^{34}$, Mariana Bettencourt Viana $^{35}$, Isaura Terra ${ }^{35}$, Vitória Rodrigues ${ }^{36}$, Sofia Marques ${ }^{36}$, Joana Selada ${ }^{36}$, Patrícia Pereira ${ }^{36}$, Jesuína Duarte ${ }^{37}$, Paula Pinto ${ }^{38}$, Ezequiel Moreira ${ }^{39}$, Adília Vicente ${ }^{41}{ }^{2}$ Centro Hospitalar de Lisboa Central, Lisboa, Portugal, ${ }^{3}$ Centro Hospitalar do Algarve, Faro e Portimão, Portugal. ${ }^{4}$ Hospital de Cascais, Cascais, Portugal. ${ }^{5}$ Centro Hospitalar de Coimbra, Coimbra, Portugal. ${ }^{6}$ Centro Hospitalar de Entre Douro e Vouga, Santa Maria da Feira, Portugal. ${ }^{7}$ Hospital Distrital da Figueira da Foz, Figueira da Foz, Portugal. ${ }^{8}$ Centro Hospitalar Lisboa Norte, Lisboa, Portugal. ${ }^{9}$ Centro Hospitalar Lisboa Ocidental, Lisboa, Portugal. ${ }^{10}$ Centro Hospitalar de Vila Nova de Gaia/Espinho, Vila Nova de Gaia e Espinho, Portugal. ${ }^{11}$ Centro Hospitalar do Alto Ave, Guimarães, Portugal. ${ }^{12}$ Centro Hospitalar do Baixo Alentejo, Beja, Portugal. ${ }^{13}$ Centro Hospitalar do Porto, Porto, Portugal. ${ }^{14}$ Centro Hospitalar da Póvoa do Varzim/Vila do Conde, Póvoa do Varzim e Vila do Conde, Portugal. ${ }^{15}$ Centro Hospitalar de Trás os Montes e Alto Douro, Vila Real e Peso da Régua e Chaves, Chaves, Portugal. ${ }^{17}$ Hospital Central do Funchal, Funchal, Portugal. ${ }^{19}$ Hospital de Santa Luzia, Elvas, Portugal. ${ }^{20}$ Hospital de Santo André, Leiria, Portugal. ${ }^{21}$ Centro Hospitalar de São João, Porto, Portugal. ${ }^{22}$ Hospital de Braga, Braga, Portugal. ${ }^{23}$ Hospital José Maria Grande, Portalegre, Portugal. ${ }^{24}$ Hospital do Espírito Santo, Évora, Portugal. ${ }^{25}$ Hospital dos SAMS, Lisboa, Portugal. ${ }^{26}$ Hospital Fernando da Fonseca, Amadora, Portugal. ${ }^{27}$ Hospital Garcia de Orta, Almada, Portugal. ${ }^{28}$ Hospital Infante D. Pedro, Aveiro, Portugal. ${ }^{29}$ Hospital de São Teotónio, Viseu, Portugal. ${ }^{30}$ Hospital Pedro Hispano, Matosinhos, Portugal. ${ }^{32}$ Hospital Reynaldo dos Santos, Vila Franca de Xira, Portugal. ${ }^{33}$ Centro Hospitalar do Alto Minho, Ponte de Lima e Viana do Castelo, Portugal. ${ }^{34}$ Hospital CUF Descobertas, Lisboa, Portugal; Laboratórios Germano de Sousa, Portugal. ${ }^{35}$ Centro Hospitalar do Tâmega e Sousa, Amarante e Guilhufe, Portugal. ${ }^{36}$ Hospital Beatriz Ângelo, Loures, Portugal; Hospital de Cascais, Cascais, Portugal; Hospitais Lusíadas, Portugal; Hospitais Luz, Portugal. ${ }^{37}$ Centro Hospitalar de Setúbal, Setúbal, Portugal. ${ }^{38}$ Hospital Distrital de Santarém, Santarém, Portugal. ${ }^{39}$ Centro Hospitalar do Médio Ave, Santo Tirso e Vila Nova de Famalicão, Famalicão, Portugal. ${ }^{41}$ Centro Hospitalar do Oeste Norte, Caldas da Rainha, Portugal. ${ }^{42}$ Hospital da Luz, Lisboa, Portugal. ${ }^{44}$ Centro Hospitalar do Nordeste, Bragança, Macedo de Cavaleiros e Mirandela, Portugal. ${ }^{45}$ Hospital Amato Lusitano, Castelo Branco, Portugal. ${ }^{46}$ Centro Hospitalar da Cova da Beira, Covilhã, Portugal. ${ }^{47}$ Hospital Sousa Martins, Guarda, Portugal. ${ }^{48}$ IPO, Lisboa, Portugal. ${ }^{49}$ Hospital Lusíadas, Lisboa, Portugal. ${ }^{50}$ Hospital Cruz Vermelha, Lisboa, Portugal. ${ }^{51}$ Centro Hospitalar do Médio Tejo, Abrantes, Portugal. ${ }^{52}$ Centro Hospitalar do Barreiro Montijo, Barreiro Montijo, Portugal. ${ }^{53}$ Hospital de Santo Espírito, Angra do Heroísmo, Portugal. ${ }^{54}$ Hospital da Horta, Horta, Portugal. ${ }^{55}$ Hospital do Divino Espírito Santo, Ponta Delgada, Portugal.

Conflicts of Interest: J.M.-C. has received research grants administered through his university and received honoraria for serving on the speakers bureaus of Pfizer and Merck Sharp and Dohme. M.R. has received honoraria for serving on the speakers bureau of Pfizer and for consulting for GlaxoSmithKline and Merck Sharp and Dohme. The funders had no role in the design of the study; in the collection, analyses, or interpretation of data; in the writing of the manuscript, or in the decision to publish the results.

\section{References}

1. Horácio, A.N.; Silva-Costa, C.; Lopes, J.P.; Ramirez, M.; Melo-Cristino, J.; Portuguese Group for the Study of Streptococcal Infections. Serotype 3 Remains the Leading Cause of Invasive Pneumococcal Disease in Adults in Portugal (2012-2014) despite Continued Reductions in Other 13-Valent Conjugate Vaccine Serotypes. Front. Microbiol. 2016, 7, 1616. [CrossRef]

2. Horácio, A.N.; Diamantino-Miranda, J.; Aguiar, S.I.; Ramirez, M.; Melo-Cristino, J.; The Portuguese Group for the Study of Streptococcal Infections. The Majority of Adult Pneumococcal Invasive Infections in Portugal Are Still Potentially Vaccine Preventable in Spite of Significant Declines of Serotypes 1 and 5. PLoS ONE 2013, 8, e73704. [CrossRef]

3. Horácio, A.N.; Diamantino-Miranda, J.; Aguiar, S.I.; Ramirez, M.; Melo-Cristino, J.; The Portuguese Group for the Study of Streptococcal Infections. Serotype Changes in Adult Invasive Pneumococcal Infections in Portugal Did Not Reduce the High Fraction of Potentially Vaccine Preventable Infections. Vaccine 2012, 30, 218-224. [CrossRef] [PubMed] 
4. De Miguel, S.; Domenech, M.; González-Camacho, F.; Sempere, J.; Vicioso, D.; Sanz, J.C.; García Comas, L.; Ardanuy, C.; Fenoll, A.; Yuste, J. Nationwide Trends of Invasive Pneumococcal Disease in Spain (2009-2019) in Children and Adults during the Pneumococcal Conjugate Vaccine Era. Clin. Infect. Dis. 2021, in press. [CrossRef] [PubMed]

5. Regev-Yochay, G.; Paran, Y.; Bishara, J.; Oren, I.; Chowers, M.; Tziba, Y.; Istomin, V.; Weinberger, M.; Miron, D.; Temper, V.; et al. Early Impact of PCV7/PCV13 Sequential Introduction to the National Pediatric Immunization Plan, on Adult Invasive Pneumococcal Disease: A Nationwide Surveillance Study. Vaccine 2015, 33, 1135-1142. [CrossRef] [PubMed]

6. Waight, P.A.; Andrews, N.J.; Ladhani, S.N.; Sheppard, C.L.; Slack, M.P.E.; Miller, E. Effect of the 13-Valent Pneumococcal Conjugate Vaccine on Invasive Pneumococcal Disease in England and Wales 4 Years after Its Introduction: An Observational Cohort Study. Lancet Infect. Dis. 2015, 15, 535-543. [CrossRef]

7. Costa, R.P.; Gonçalves, C.; Sousa, J.C. de A doença pneumocócica e recomendações GRESP para a vacinação antipneumocócica na população adulta ( $\geq 18$ anos). Rev. Port. Med. Geral E Fam. 2016, 32, 70-74.

8. Direcção Geral de Saúde Norma 11/2015-Vacinação Contra Infeções Por Streptococcus Pneumoniae de Grupos Com Risco Acrescido Para Doença Invasiva Pneumocócica (DIP). Adultos ( $\geq 18$ Anos de Idade). 2015. Available online: http://nocs.pt/wpcontent/uploads/2017/11/i021902.pdf (accessed on 11 May 2016).

9. Sousa, M.; Cavadas, L.F.; Santos, R.B.; Macedo, A. Avaliação Da Qualidade Da Prescrição Da Vacina Anti-Pneumocócica Aos Idosos. Rev. Port. Clín. Geral 2009, 25, 531-536. [CrossRef]

10. Hurley, D.; Griffin, C.; Young, M.; Scott, D.A.; Pride, M.W.; Scully, I.L.; Ginis, J.; Severs, J.; Jansen, K.U.; Gruber, W.C.; et al. Safety, Tolerability, and Immunogenicity of a 20-Valent Pneumococcal Conjugate Vaccine (Pcv20) in Adults 60 to 64 Years of Age. Clin. Infect. Dis. 2020, in press. [CrossRef]

11. Peterson, J.T.; Stacey, H.L.; MacNair, J.E.; Li, J.; Hartzel, J.S.; Sterling, T.M.; Benner, P.; Tamms, G.M.; Musey, L.K. Safety and Immunogenicity of 15-Valent Pneumococcal Conjugate Vaccine Compared to 13-Valent Pneumococcal Conjugate Vaccine in Adults $\geq 65$ Years of Age Previously Vaccinated with 23-Valent Pneumococcal Polysaccharide Vaccine. Hum. Vaccines Immunother. 2019, 15, 540-548. [CrossRef]

12. Serrano, I.; Ramirez, M.; Melo-Cristino, J.; Portuguese Surveillance Group for the Study of Respiratory Pathogens. Invasive Streptococcus Pneumoniae from Portugal: Implications for Vaccination and Antimicrobial Therapy. Clin. Microbiol. Infect. 2004, 10, 652-656. [CrossRef]

13. Sørensen, U.B. Typing of Pneumococci by Using 12 Pooled Antisera. J. Clin. Microbiol. 1993, 31, 2097-2100. [CrossRef]

14. Spencer, B.L.; Shenoy, A.T.; Orihuela, C.J.; Nahm, M.H. The Pneumococcal Serotype 15C Capsule Is Partially O-Acetylated and Allows for Limited Evasion of PPV23-Elicited Anti-Serotype 15B Antibodies. Clin. Vaccine Immunol. CVI 2017, 24, e00099-17. [CrossRef] [PubMed]

15. Clinical and Laboratory Standards Institute. Performance Standards for Antimicrobial Susceptibility Testing, 28th ed.; Clinical and Laboratory Standards Institute: Wayne, PA, USA, 2018.

16. Melo-Cristino, J.; Ramirez, M.; Serrano, N.; Hänscheid, T.; The Portuguese Surveillance Group for the Study of Respiratory Pathogens. Macrolide Resistance in Streptococcus Pneumoniae Isolated from Patients with Community-Acquired Lower Respiratory Tract Infections in Portugal: Results of a 3-Year (1999-2001) Multicenter Surveillance Study. Microb. Drug Resist. 2003, 9, 73-80. [CrossRef]

17. Carriço, J.A.; Silva-Costa, C.; Melo-Cristino, J.; Pinto, F.R.; de Lencastre, H.; Almeida, J.S.; Ramirez, M. Illustration of a Common Framework for Relating Multiple Typing Methods by Application to Macrolide-Resistant Streptococcus Pyogenes. J. Clin. Microbiol. 2006, 44, 2524-2532. [CrossRef] [PubMed]

18. Benjamini, Y.; Hochberg, Y. Controlling the False Discovery Rate-A Practical and Powerful Approach to Multiple Testing. J. R. Stat. Soc. Ser. B Stat. Methodol. 1995, 57, 289-300. [CrossRef]

19. Shiri, T.; Datta, S.; Madan, J.; Tsertsvadze, A.; Royle, P.; Keeling, M.J.; McCarthy, N.D.; Petrou, S. Indirect Effects of Childhood Pneumococcal Conjugate Vaccination on Invasive Pneumococcal Disease: A Systematic Review and Meta-Analysis. Lancet Glob. Health 2017, 5, e51-e59. [CrossRef]

20. Hanquet, G.; Krizova, P.; Valentiner-Branth, P.; Ladhani, S.N.; Nuorti, J.P.; Lepoutre, A.; Mereckiene, J.; Knol, M.; Winje, B.A.; Ciruela, P.; et al. Effect of Childhood Pneumococcal Conjugate Vaccination on Invasive Disease in Older Adults of 10 European Countries: Implications for Adult Vaccination. Thorax 2019, 74, 473-482. [CrossRef] [PubMed]

21. Ouldali, N.; Varon, E.; Levy, C.; Angoulvant, F.; Georges, S.; Ploy, M.-C.; Kempf, M.; Cremniter, J.; Cohen, R.; Bruhl, D.L.; et al. Invasive Pneumococcal Disease Incidence in Children and Adults in France during the Pneumococcal Conjugate Vaccine Era: An Interrupted Time-Series Analysis of Data from a 17-Year National Prospective Surveillance Study. Lancet Infect. Dis. 2021, 21, 137-147. [CrossRef]

22. Amin-Chowdhury, Z.; Collins, S.; Sheppard, C.; Litt, D.; Fry, N.K.; Andrews, N.; Ladhani, S.N. Characteristics of Invasive Pneumococcal Disease Caused by Emerging Serotypes after the Introduction of the 13-Valent Pneumococcal Conjugate Vaccine in England: A Prospective Observational Cohort Study, 2014-2018. Clin. Infect. Dis. 2020, 71, e235-e243. [CrossRef] [PubMed]

23. Ludwig, G.; Garcia-Garcia, S.; Lanaspa, M.; Ciruela, P.; Esteva, C.; Fernandez de Sevilla, M.; Diaz-Conradi, A.; Marti, C.; Motje, M.; Galles, C.; et al. Serotype and Clonal Distribution Dynamics of Invasive Pneumococcal Strains after PCV13 Introduction (2011-2016): Surveillance Data from 23 Sites in Catalonia, Spain. PLoS ONE 2020, 15, e0228612. [CrossRef] [PubMed] 
24. Wijayasri, S.; Hillier, K.; Lim, G.H.; Harris, T.M.; Wilson, S.E.; Deeks, S.L. The Shifting Epidemiology and Serotype Distribution of Invasive Pneumococcal Disease in Ontario, Canada, 2007-2017. PLoS ONE 2019, 14, e226353. [CrossRef] [PubMed]

25. Zintgraff, J.; Fossati, S.; Pereira, C.S.; Veliz, O.; Regueira, M.; Moscoloni, M.A.; Irazu, L.; Lara, C.; Napoli, D.; Argentina Spn Working Group. Distribution of PCV13 and PPSV23 Streptococcus Pneumoniae Serotypes in Argentinean Adults with Invasive Disease, 2013-2017. Rev. Argent. Microbiol. 2020, 52, 189-194. [CrossRef] [PubMed]

26. Yanagihara, K.; Kosai, K.; Mikamo, H.; Mukae, H.; Takesue, Y.; Abe, M.; Taniguchi, K.; Petigara, T.; Kaku, M. Serotype Distribution and Antimicrobial Susceptibility of Streptococcus Pneumoniae Associated with Invasive Pneumococcal Disease among Adults in Japan. Int. J. Infect. Dis. 2021, 102, 260-268. [CrossRef]

27. Lewnard, J.A.; Hanage, W.P. Making Sense of Differences in Pneumococcal Serotype Replacement. Lancet Infect. Dis. 2019, 19, e213-e220. [CrossRef]

28. Hespanhol, V.; Bárbara, C. Pneumonia Mortality, Comorbidities Matter? Pulmonology 2020, 26, 123-129. [CrossRef] 